\title{
Los diccionarios escolares a comienzos del siglo XXI
}

\author{
Trinidad Sánchez Muñoz \\ Centro de Investigaciones Lingüisticas de la \\ Universidad de Salamanca (CILUS)
}

\section{O. DEFICIENCIAS DE LA LEXICOGRAFÍA ESCOLAR ACTUAL}

Desde 1990 -año inaugural de la LOGSE-, se han publicado, según nuestra revisión bibliográfica, más de una veintena de diccionarios dirigidos a los alumnos de Enseñanza Secundaria. Aunque los nuevos diccionarios escolares son más didácticos que los de décadas anteriores -entre éstos últimos, como han puesto de manifiesto Martínez Marín (1991: 63) y Hernández (1996: 28), sólo el Diccionario Anaya de la lengua (1979) y el Diccionario escolar de la lengua española Vox (1976) podían considerarse herramientas pedagógicas-, todavía presentan deficiencias que revelan que no se han tenido en cuenta las necesidades de uso de sus destinatarios. De hecho, la mayoría de ellos no establece la diferencia entre la Enseñanza Secundaria Obligatoria (de doce a dieciséis años) y la Enseñanza Secundaria Posobligatoria o Bachillerato (de dieciséis a dieciocho años), dos niveles que, a la hora de elaborar un diccionario escolar, deben separarse, ineludiblemente, si lo que se pretende es hacer una obra cuya única pretensión sea la de ser un instrumento para enseñar a comprender y a escribir: a un alumno de doce años no le es útil la información destinada al de diecisiete o dieciocho años, y viceversa; sin embargo, para que el mismo diccionario sea válido para los dos grupos de alumnos, a todos les pesará demasia-

1 La encuesta de este estudio la dirigió José Luis Herrero, director del Centro de Investigaciones Lingüísticas de la Universidad de Salamanca. 
do, física e intelectualmente, un libro que pretende cubrir intereses tan diversos.

La indeterminación de la edad y el olvido de la capacidad compresiva de sus usuarios son los responsables de la mayor parte de los defectos que persisten en estas obras, como el del empleo de definiciones incomprensibles para los más jóvenes. Un ejemplo del desconocimiento de las necesidades del consultor de estos diccionarios lo representa el DERAE (Diccionario escolar de la Real Academia Española), publicado en 1996. El criterio seguido para "adaptar el diccionario general de la RAE al uso escolar", como se señala en el prólogo, fue el de reducir el tamaño de su diccionario general a 33.000 artículos. Si exceptuamos los dos apéndices (ortográfico y gramatical), la tonalidad azul para resaltar el lema y las ilustraciones en color, no puede considerarse un diccionario apto para el ámbito escolar, debido, entre otras razones, a que los ejemplos son escasísimos, no se ha seguido un criterio riguroso en la selección de las acepciones, y a que las definiciones no se han redactado teniendo en cuenta a los estudiantes. Basta con repasar cualquier página de esta obra para comprobar estos tres defectos; no obstante, el artículo dedicado a paje es uno de los que mejor los ilustra: la única acepción de esta voz que recoge el $D E R A E$ es la primera del $D R A E$, las demás se han suprimido; por otra parte, las definiciones de ambos diccionarios son iguales (usamos la vigésima primera edición; en la vigésima segunda, la de 2001, lo único que se cambia es el tiempo verbal, que, después de haber resistido más de dos siglos, pasa de presente a pasado):

paje. $m$. Criado cuyo ejercicio es acompañar a sus amos, asistir en las antesalas, servir a la mesa y otros ministerios decentes y domésticos.

A propósito del estilo conservador del DRAE, Seco (1995: 71) manifestó que "en muchas definiciones se le ha quedado parado el reloj". Si para cualquier consultor adulto este lenguaje resulta arcaico y extraño, para el de un diccionario pedagógico es aún más inapropiado, pues no se adecua ni a la época ni a sus capacidades comprensivas. La única innovación que aporta el artículo de la palabra paje en el DERAE es, exclusivamente, la de haber recortado el resto de las acepciones. Hasta 
tal punto esta obra es una abreviación del Diccionario general de la Academia que, para evitar las pistas perdidas producidas por la supresión de algunas entradas y acepciones, se ven en la obligación de explicar entre corchetes las palabras del Diccionario general eliminadas en el escolar. Desaparecen las pistas perdidas, pero el problema de base no se corrige: la obra no se ha planificado pensando en sus usuarios, hecho que trae consigo que falten campos de obligada presencia en un diccionario pedagógico y que sobren abreviaturas que desorientan al alumno $^{2}$.

La editorial SM, bajo la dirección de Concepción Maldonado, publicó, en 1993, Intermedio, un diccionario destinado a los alumnos de ESO (de doce a dieciséis años). La necesidad de reducir el volumen de este diccionario fue, quizás, la razón que les llevó a disminuir el número de ejemplos en un diccionario posterior, Avanzado, de 1998. Éste nació, probablemente, con la intención de ocupar el lugar de Intermedio; sin embargo, no posee la misma calidad, ya que, a pesar de que mantiene el plan general, al introducir información etimológica y al aumentar el corpus definido, no incluye, frente a Intermedio, un ejemplo en cada una de las acepciones. Opera tal simplificación de los ejemplos que, en las aulas en las que debe usarse, se echa de menos la ejemplificación. Por otro lado, y como consecuencia de los cambios, en Avanzado no se especifica el grupo de alumnos a los que se dirige; Intermedio, por el contrario, sí determina que sus destinatarios son los chicos con edades comprendidas entre doce y dieciséis años. El hecho de suprimir en Avanzado dos de sus mayores logros (la inclusión de un ejemplo por acepción y la especificación clara del destinatario) debe de haber sido el motivo que ha llevado a la editorial SM a reeditar, en el año 2000, su diccionario Intermedio, uno de los mejores productos de la lexicografía escolar en español.

Pérez Lagos (1998: 115) afirma que las aportaciones a favor de la renovación lexicográfica se están produciendo gracias a las editoriales

2 Parece que uno de los proyectos de la Institución es el de crear un nuevo diccionario escolar. 
especializadas en la elaboración de libros de texto, dado que "las editoriales tradicionalmente dedicadas al diccionario se afanan todos los años en sacar a la luz nuevas obras, muchas de ellas con el título de escolares, pero todas ellas muestran una continuidad en el estilo y forma con respecto a las obras mayores de las que proceden". A pesar de este reconocimiento, en el artículo citado, expone los errores que mantienen los tres diccionarios que considera verdaderamente innovadores. Las obras objeto de su estudio son: Diccionario esencial Santillana, Diccionario Anaya de la lengua y SM Diccionario Intermedio. En el análisis de la última obra, al contrario que en las otras dos, el autor se detiene en repasar una importante serie de aciertos: la abundancia de ejemplos, la selección de neologismos y extranjerismos, la disposición tipográfica de cada artículo, la información sobre el uso normativo y los cuadros y apéndices.

Azorín, mediante el análisis de los resultados de una encuesta que aplicó en Alicante a estudiantes de Primaria, ESO y COU, llegó a la siguiente conclusión:

A pesar del indudable avance experimentado por la lexicografía escolar, los diccionarios siguen presentando, a juicio de sus usuarios habituales, importantes deficiencias, principalmente:

- En cuanto a la cantidad y calidad de las voces que registran.

- En el tratamiento de la fraseología.

- En la formulación de las definiciones.

—En la ejemplificación.

- En las ilustraciones.

Debido a estas deficiencias y a la falta de formación en su manejo, los escolares no alcanzan a explotar todas las posibilidades que, al menos en teoría, el diccionario les brinda. Por lo que el uso queda limitado en la mayoría de los casos a buscar el significado de las palabras, comprobar la ortografía y a la búsqueda de sinónimos y antónimos (2000: 78).

Por último, es importante resaltar que en muy pocos de los diccionarios escolares publicados recientemente se repiten los defectos más graves en que incurrían habitualmente los anteriores a 1990: nos encontramos menos casos de definiciones circulares; escasas veces aparecen 
pistas perdidas -en el Nuevo diccionario esencial Santillana (2000) persisten algunas de las que aparecían en la edición de 1991-, y las definiciones no obligan a efectuar repetidas búsquedas. No obstante, no existen, salvo excepciones, verdaderos diccionarios didácticos que ayuden a los alumnos a resolver los problemas que se les plantean al realizar sus tareas. Se ha progresado en el campo de la lexicografía escolar incorporando cambios que contribuyen a que los diccionarios escolares sean obras cada vez más didácticas, pero hay que mejorar muchos aspectos.

\section{RESULTADOS DE LA ENCUESTA REALIZADA EN SALAMANCA Y PROVINCIA DURANTE 1999}

A partir de la constatación de que, salvo casos aislados, la lexicografía escolar había evolucionado poco en la última década - tan prolija en diccionarios escolares-, durante el curso escolar 1999, el Centro de Investigaciones Lingüísticas de la Universidad de Salamanca (CILUS) acometió el trabajo de perfilar las características que debía contener un diccionario escolar "ideal". Para ello, desarrolló dos líneas de trabajo convergentes: por un lado, se estudiaron comparativamente veintitrés diccionarios escolares; por otro, se realizó una consulta a sus usuarios, a través de una encuesta dirigida a alumnos y profesores de ESO y Bachillerato de Salamanca y provincia.

Los cuestionarios se confeccionaron teniendo como modelo los usados en encuestas anteriores -Hernández (1989), Perdiguero (1997) y Azorín (1998)-. Siguiendo el planteamiento metodológico de esta autora, elaboramos un cuestionario con preguntas cerradas: eliminamos las abiertas y les ofrecimos a los encuestados diferentes opciones de respuesta. Así, todas las personas que lo cumplimentaron respondieron sin dificultad a las veintinueve preguntas, dado que, para evitar la vaguedad, se formularon de manera que cualquiera, aunque no fuera especialista, pudiera contestar con rigor. Éste es un método muy laborioso, que obliga a trabajar despacio en la redacción de los cuestionarios, pero el grado de información resultante ha sido muy valiosa y precisa para nuestro análisis, cuyos resultados nos han ayudado a conocer el grado 
de satisfacción de los usuarios; la situación y el nivel de adaptación de los materiales lexicográficos al mundo escolar; la frecuencia y circunstancias del aprendizaje; los tipos de diccionarios que utilizan; el uso que hacen de los mismos; los fallos que advierten en ellos; las voces que no encuentran; la cualidad que más les gusta, y las definiciones preferidas $^{3}$.

El tamaño total de la muestra - extraída de las cifras de profesores que trabajaban en los centros de Salamanca y provincia y del cómputo de alumnos matriculados en $1 .^{\circ}, 2 .^{\circ}, 3 .^{\circ}$ y $4 .^{\circ}$ de ESO; $1 .^{\circ}$ y $2 .^{\circ}$ de $\mathrm{Ba}-$ chillerato-LOGSE; $2 .^{\circ}$ y $3 .^{\circ}$ de BUP; COU, y $1 .^{\circ}$ y $2 .^{\circ}$ de los Ciclos Formativos de Grado Medio- ha sido el siguiente: 250 profesores (194 pertenecientes a centros públicos y 56 a centros privados) y 915 alumnos (500 de centros públicos y 415 de centros privados).

En la encuesta de profesores, hemos dividido a la población en los estratos rural/urbano, público/privado, cursos en los que imparten clase y departamento al que pertenecen. La destinada a los alumnos, además de los estratos rural/urbano, público/ privado, incluye la edad, el sexo, los estudios que cursan, el lugar de residencia habitual y los estudios realizados por sus padres.

Dadas las dimensiones del estudio, incluimos un resumen de los resultados de los cincuenta y ocho campos que abarcan los cuestionarios de alumnos y profesores"

1. El elevado número de diccionarios escolares publicados durante los últimos diez años no ha modificado los criterios de selección de es-

3 Los datos obtenidos han servido para llevar a cabo el diseño y la elaboración de un diccionario escolar de producción y comprensión, adecuado a la competencia lingüística de los alumnos de la ESO y a sus necesidades concretas de uso. Pretendemos dar respuesta a las deficiencias que los destinatarios de los diccionarios pedagógicos -los profesores y los alumnos- revelan en la encuesta, y crear una herramienta básica para la adquisición del vocabulario.

4 El trabajo estadístico lo llevaron a cabo Inmaculada Barrera y M. ${ }^{a}$ José Fernández, profesoras del Departamento de Estadística de la Facultad de Economía y Empresa de Salamanca. 
tas obras: a excepción del Diccionario escolar de la Real Academia Española (1996), los diccionarios más utilizados y difundidos entre la población escolar han aparecido hace más de veinte años.

2. Pese a que la lexicografía escolar ha progresado notablemente durante la última década, se mantienen graves deficiencias: la escasa claridad de las definiciones; la insuficiencia de ejemplos; la inadecuación del léxico registrado a las necesidades escolares, y la falta de rigor en el tratamiento de las frases hechas y colocaciones léxicas.

3. Las cualidades de los diccionarios escolares preferidas por los encuestados son: la claridad de las definiciones, los ejemplos, las ilustraciones y la presencia de los términos buscados.

4. Las palabras que, según los profesores, no deben faltar nunca en un diccionario son las generales y los tecnicismos.

5. A pesar del reconocido prestigio de que gozan los diccionarios como herramienta clave para el desarrollo de las capacidades comprensivas y expresivas, casi la totalidad de los encuestados considera que es el medio que menos ayuda a aprender.

\begin{tabular}{|l|r|r|r|c|}
\hline Medios de más ayuda & Pub-ESO & Pub-Bach & Pri-ESO & Pri-Bach \\
\hline LIBROS TEXTO & 36,76 & 50,26 & 33,91 & 34,01 \\
\hline LIBROS LECTURA & 13,83 & 23,04 & 23,56 & 22,84 \\
\hline DICCIONARIOS & 3,56 & 1,57 & 4,02 & 1,02 \\
\hline ENCICLOPEDIAS & 30,44 & 16,75 & 25,29 & 14,21 \\
\hline PRENSA & 3,95 & 2,62 & 5,17 & 11,68 \\
\hline TELEVISIÓN & 11,46 & 5,76 & 8,05 & 16,24 \\
\hline
\end{tabular}

Tabla 1. Porcentajes de respuesta al ítem 23 según el nivel de estudios y el tipo de centro.

Con respecto a la utilidad que los diccionarios reportan, la situación apenas ha variado desde que Alvar Ezquerra (1982: 49-53) 1lamó la atención a todos los que tienen alguna responsabilidad, libreros, padres, 
autoridades académicas y usuarios, para hacer posible la difusión y el conocimiento de los contenidos de los diccionarios. Según sus respuestas, los alumnos aprenden a utilizar el diccionario en Primaria; sin embargo, existe una gran desinformación sobre todas las posibilidades de uso que éste ofrece. Se explota solo la función descodificadora del diccionario, puesto que se sigue utilizando para buscar el significado de los vocablos desconocidos (un 100\%); saber cómo se escriben las palabras (casi un 75\%), y buscar sinónimos (un 50\%).

\begin{tabular}{|l|c|c|c|}
\hline ¿Para qué usas el diccionario? & Sí & NO & NS/NC \\
\hline CONOCER SIGNIFICADO & 880 & 27 & 2 \\
\hline VER QUÉ ES & 221 & 672 & 16 \\
\hline CONOCER GÉNERO & 245 & 746 & 18 \\
\hline CÓMO SE ESCRIBE & 696 & 206 & 7 \\
\hline BUSCAR EJEMPLOS & 454 & 438 & 17 \\
\hline CULTA/VULGAR & 130 & 761 & 18 \\
\hline PLURAL & 79 & 813 & 17 \\
\hline SINÓNIMOS/ANTÓNIMOS & 537 & 360 & 12 \\
\hline TILDE & 408 & 487 & 14 \\
\hline PRON. EXTRANJERA & 264 & 629 & 16 \\
\hline ORIGEN PALABRA & 261 & 635 & 13 \\
\hline
\end{tabular}

Tabla 2. Distribución de frecuencias de las respuestas a las preguntas planteadas en el ítem 18 (¿Para qué usas el diccionario?).

7. Los alumnos de Bachillerato - frente a sus compañeros de ESO, que no lo hacen nunca- usan alguna vez el diccionario con finalidades productivas; pero recurren a él con menor frecuencia que en la ESO. De hecho, a medida que el nivel de estudios aumenta, disminuye la utilización del diccionario. Como revelan los resultados de la encuesta, su uso depende, en muchos casos, de que se lo "mande el profesor". 
8. Los docentes demuestran un claro desinterés por adiestrar a sus discípulos en el manejo del diccionario, excepto los que imparten la asignatura de Lengua Castellana y Literatura y algunos de otras disciplinas humanísticas. Por su parte, los alumnos manifiestan que solo utilizan los diccionarios en clase de Lengua Castellana y Literatura.

9. Los profesores de Lengua Castellana y Literatura disponen de mayor información sobre los diccionarios que el resto de los docentes; así mismo, frente a sus compañeros, que opinan que la enseñanza del uso del diccionario debe recaer sobre los profesores de Lengua Castellana y Literatura, manifiestan que ha de ser una tarea compartida por todos.

10. La mayoría de los docentes desconoce la oferta editorial, salvo el Diccionario de la lengua española de la Real Academia y el Diccionario de uso del español, de María Moliner. Debido a la amplia difusión del Diccionario académico -conocido por más de un 95\%-, los demás diccionarios, si exceptuamos a la población representada por los profesores de Lengua Castellana y Literatura, son casi desconocidos.

11. A pesar del alto grado de aceptación de los diccionarios publicados por la Real Academia de la Lengua Española, los docentes, a la hora de decidir entre dos artículos - uno de ellos extraído del Diccionario general de la Real Academia-, escogen el del diccionario que apenas conocen.

12. Los diccionarios electrónicos no han arraigado apenas en ningún colectivo del ámbito escolar.

\section{ESTUDIO COMPARATIVO DE LA ENCUESTA DE SALAMANCA CON TRES ENCUESTAS ANTERIORES}

El hecho más llamativo y desalentador es que los datos que revela nuestra encuesta no varían apenas de los que aportó la de Hernández, realizada en Tenerife, en 1989, aunque ya pretendía ser un aldabonazo sobre las conciencias de lexicógrafos, profesores y usuarios. Además de los resultados de esta encuesta, exponemos los de la de Perdiguero, llevada a cabo en Burgos, en 1997; y los de Azorín, en Alicante, entre 1997 y 1998. 
De las distintas preguntas a las que responden todos los encuestados, solamente compararemos las que atañen a las deficiencias y aciertos de los diccionarios. Así mismo, restringimos este análisis comparativo a los datos obtenidos en relación con los alumnos, debido a que la encuesta de Alicante no incluyó a los profesores. Hay que señalar, también, que los estudiantes de Burgos son universitarios, frente a los de Alicante y Salamanca que pertenecen exclusivamente a Enseñanza Secundaria (ESO, Bachillerato, COU, Bachillerato-LOGSE y Ciclos formativos de Grado Medio); y a EGB, Bachillerato, COU, alumnos de la Escuela de Magisterio y a medio centenar de recién licenciados, los de Tenerife:

\section{Deficiencias encontradas en tu diccionario (por orden de frecuencia):}

\begin{tabular}{|c|c|c|c|}
\hline Tenerife (1989) & Burgos (1997) & Alicante (1998) & Salamanca (1999) \\
\hline $\begin{array}{l}\text { - Faltan palabras } \\
\text { - No define con } \\
\text { claridad } \\
\text { - No pone } \\
\text { ejemplos }\end{array}$ & $\begin{array}{l}\text { - Las definiciones } \\
\text { no son claras } \\
\text { - Faltan palabras } \\
\text { - No se entienden } \\
\text { las abreviaturas } \\
\text { - No hay ejemplos }\end{array}$ & $\begin{array}{l}\text { - No es fácil } \\
\text { encontrar las } \\
\text { frases hechas } \\
\text { - Las definiciones } \\
\text { no son claras } \\
\text { - No hay } \\
\text { suficientes } \\
\text { ejemplos }\end{array}$ & $\begin{array}{l}\text { - No es fácil } \\
\text { encontrar las } \\
\text { frases hechas } \\
\text { - Faltan palabras } \\
\text { - No tiene normas } \\
\text { para escribir las } \\
\text { palabras } \\
\text { difíciles } \\
\text { - No trae } \\
\text { ejemplos }\end{array}$ \\
\hline
\end{tabular}

Tabla 3.

\section{CUALIDADES PREFERIDAS DE TU DICCIONARIO}

\begin{tabular}{|c|c|c|c|}
\hline Tenerife (1989) & Burgos (1997) & Alicante (1998) & Salamanca (1999) \\
\hline $\begin{array}{l}\text { - Pregunta no } \\
\text { incluida en la } \\
\text { encuesta }\end{array}$ & - Los ejemplos & $\begin{array}{l}\text { - Encontrar todas } \\
\text { las palabras } \\
\text { - Las ilustraciones } \\
\text { - La información } \\
\text { enciclopédica }\end{array}$ & $\begin{array}{l}\text { - La claridad de } \\
\text { las definiciones } \\
\text { - Las ilustraciones } \\
\text { - Los ejemplos }\end{array}$ \\
\hline
\end{tabular}


3. DICCIONARIO PREFERIDO

\begin{tabular}{|c|c|c|c|}
\hline Tenerife (1989) & Burgos (1997) & Alicante (1998) & Salamanca (1999) \\
\hline $\begin{array}{l}\text { - Iter-Sopena. } \\
\text { Diccionario } \\
\text { ilustrado de la } \\
\text { lengua española } \\
\text { - Diccionario } \\
\text { Anaya de la } \\
\text { lengua }\end{array}$ & $\begin{array}{l}\text { - Larousse. } \\
\text { Diccionario de } \\
\text { la lengua. } \\
\text { Júnior } \\
\text { - Gran } \\
\text { diccionario } \\
\text { Everest de la } \\
\text { lengua española }\end{array}$ & - No determinado & $\begin{array}{l}\text { - Vox. } \\
\text { Diccionario } \\
\text { escolar de la } \\
\text { lengua española } \\
\text { - Diccionario } \\
\text { Anaya de la } \\
\text { lengua }\end{array}$ \\
\hline
\end{tabular}

Tabla 5.

La encuesta de Salamanca aporta también la opinión de los profesores sobre estos mismos ítems. Al primero, deficiencias encontradas en los diccionarios escolares, responden (por orden de frecuencia):

- La falta de ejemplos en las definiciones.

- La dificultad de encontrar las expresiones formadas por varios vocablos.

- La exclusión de sinónimos y antónimos.

- La selección del léxico es inadecuada.

- La escasa claridad de las definiciones.

En cuanto a la pregunta "¿qué considera necesario mejorar en un diccionario escolar?", las tres opciones elegidas entre cinco posibilidades son:

- Las definiciones.

- Los ejemplos.

- La selección del léxico.

Por último, los diccionarios escolares preferidos por los profesores son: en primer lugar, el Diccionario escolar de la Real Academia Española; en segundo, el Diccionario Anaya de la lengua. Este dato revela, por un lado, la desinformación del profesorado salmantino acerca de los diccionarios escolares existentes; por otro, el prestigio y la influencia de la Real Academia al elegirlos. Esta es, sin duda, la razón que lleva a su diccionario escolar a colocarse a la cabeza de todos. 
Como es esperable, en la encuesta realizada en Salamanca, los alumnos, inmediatamente después de los que ocupan los dos primeros lugares (ver tabla 5), se inclinan por el de la Academia (DERAE). De modo que tres diccionarios, Vox, Anaya y DERAE, cubren casi el $60 \%$ del mercado editorial. La elección de los dos primeros se explica si tenemos en cuenta que ambos fueron los primeros diccionarios pedagógicos que aparecieron antes de 1985.

\section{CONCLUSIONES}

Los resultados de la encuesta de Salamanca, el análisis comparativo con las otras tres y la comprobación de que los diccionarios más vendidos no son los de mayor calidad, salvo en lo que se refiere a los de hace casi treinta años, ponen de manifiesto que, en la lexicografía escolar, deben producirse cambios importantes en dos ámbitos: el del aula y el de la lexicografía. A los profesores les corresponde conocer las características de las distintas obras y aconsejar a sus alumnos, responsablemente, el que se ajusta mejor a sus necesidades -los datos de la encuesta no son solo consecuencia de la calidad de las obras, sino también de la desinformación-; a los lexicógrafos, elaborar diccionarios teniendo en cuenta a destinatarios que usan estas obras para aprender, no para consultar: si uno de los principales problemas con que tropiezan los autores de los diccionarios escolares es el del volumen, hay que acotar con rigor las edades de sus usuarios para dar cabida a todos los campos que ese usuario específico necesita y excluir otros aspectos que no le sirven.

\section{BIBLIOGRAFÍA}

\section{A) Diccionarios}

Diccionario Anaya de la lengua (1979), 1. ${ }^{\mathrm{a}}$ ed , Madrid, Anaya.

Diccionario escolar de la lengua española Vox (1976), 1. a ed., Barcelona, Vox-Biblograf.

Diccionario ilustrado de la lengua española (1982), 1. ${ }^{\mathrm{a}}$ ed., Barcelona, ÍterSopena. 
Fontanillo Merino, E. (dir.) (1992): Larousse Júnior. Diccionario ciclo inicial,1. ${ }^{\text {a }}$ ed., Barcelona, Larousse.

Gran diccionario Everest de la lengua española (1995), 1. ${ }^{a}$ ed., León, Everest, 2 vols.

Maldonado GonzÁlez. C. (dir.) (1993): Diccionario didáctico del español. Intermedio, $1 .^{\text {a }}$ ed., Madrid, SM.

—_ (1998): Diccionario didáctico del español. Avanzado, 1. ${ }^{a}$ ed., Madrid, SM.

Moliner, María (1966): Diccionario de uso del español [DUE], 1. ${ }^{\text {a }}$ ed., Madrid, Gredos, 2 vols.

Real Academia Española (1992): Diccionario de la lengua española

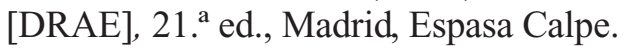

— (1996): Diccionario escolar de la lengua española [DERAE], 1. ${ }^{\mathrm{a}} \mathrm{ed}$. , Madrid, Espasa Calpe.

- (2001): Diccionario de la lengua española [DRAE], 22. ${ }^{\text {a }}$ ed., Madrid, Espasa Calpe, 2 vols.

SÁnchez Cerezo, S. (dir.) (1991): Diccionario esencial de la lengua española, 1. a ed., Madrid, Santillana.

_ (2000): Nuevo diccionario esencial de la lengua española, $1{ }^{a}{ }^{a}$ ed., Madrid, Santillana.

B) ESTUDIOS Y ARTÍCULOS

AlVAR EZquerRa, Manuel (1982): "Función del diccionario en la enseñanza de la lengua", Revista de Bachillerato, 22, pp. 49-53.

Azorín, Dolores (2000): “¿Para qué usan el diccionario los escolares? Reflexiones a propósito de una encuesta”, en Stefan Ruhstaller y Josefina Prado Aragonés (eds.), Tendencias en la investigación lexicográfica del español. El diccionario como objetivo de estudio lingüistico y didáctico, Actas del Congreso celebrado en la Universidad de Huelva del 25 al 27 de noviembre de 1998, Huelva, Universidad de Huelva, pp. $75-100$.

HERNÁNDEZ, Humberto (1989): Los diccionarios de orientación escolar: contribución al estudio de la lexicografía monolingüe española, La Laguna, Universidad de La Laguna.

_ (1996): "La lexicografía didáctica: los diccionarios escolares del español en el último cuarto de siglo", Cuadernos Cervantes, 11, pp. 24-36.

MARTíNeZ MARín, Juan (1991): "Los diccionarios escolares del español: lo que son y lo que deberían ser", en I. Ahumada (ed.): Diccionarios es- 
pañoles: contenidos y aplicaciones, I Seminario de Lexicografía Hispánica, Jaén, Universidad de Jaén, pp. 53-70.

Perdiguero, Hermógenes (1997): Encuesta sobre el uso de los diccionarios escolares, Universidad de Burgos (Documento interno inédito).

Pérez LaGos, Fernando (1998): "Los diccionarios escolares de los últimos años. ¿Una nueva lexicografía didáctica?”, en Diccionarios, frases, palabras, Málaga, Universidad de Málaga, pp. 115-125.

Seco, Manuel (1995): "Lexicografía en el fin de siglo", Donaire, 4, pp. 6774. 